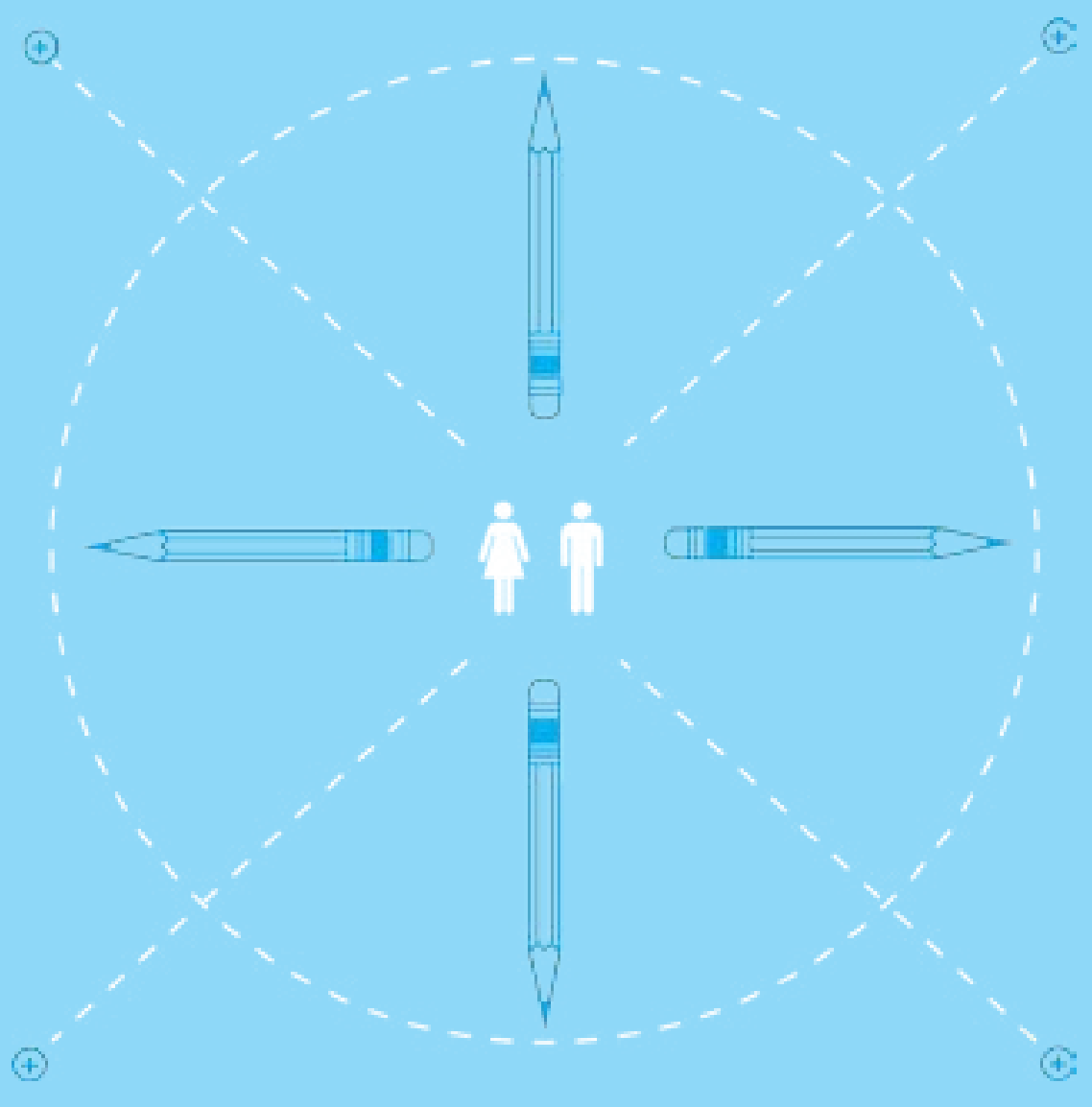

\title{
"Si mi entorno quiero conocer, leyendo y escribiendo más fácil es"
}

Una secuencia didáctica para la comprensión y producción textual, en grado primero, del Centro Integral José María Córdoba IED, 2014

"If my enviroment i want to know, reading and writing easier it is". A didactic sequence for texts production and comprenhension in first grade children from Centro Integral José María Córdoba, IED, 2014

"Se você quer saber o que me rodeia, leitura e escrita mais fácil é". Uma seqüência de ensino para a compreensão de texto e produção no primeiro grau, centro detalhado José María Córdoba IED de 2014 
Laura Liliana Sánchez Sánchez ${ }^{1}$

1 Secretaría de Educación Distrital de Bogotá; Licenciada en Educación Básica con énfasis en Lengua Castellana, Fundación Universitaria Monserrate. Correo electrónico: sanchezsanchezlauraliliana@gmail.com

Fecha de recepción: 24 de febrero de 2015 / Fecha de aprobación: 3 de abril de 2015.

\section{Resumen}

Este artículo presenta los resultados de un proyecto de investigación-acción que se realizó con niñas y niños del grado primero, del Centro Integral José María Córdoba, IED, Bogotá. El propósito fue indagar sobre estrategias pedagógicas que facilitaran la comprensión y producción textual.

El análisis de la información evidencia que los estudiantes vinculados al proceso han mejorado notablemente los niveles de comprensión y producción textual. Se observa además una mayor participación y motivación por las clases que involucran lectura, escritura y arte.

\section{Palabras clave}

Secuencia didáctica, lectura, escritura, literatura, arte, producción de textos, comprensión de textos.

\section{Summary}

This article presents the results of an action research project which was made with 1 st grade children from Centro Integral José María Córdoba, IED, Bogotá D.C. The main objective of the research was to investigate about different pedagogical strategies to make easier the text comprehension and production. The analysis of the obtained information evidences that the students linked to the process have improved the text comprehension and production levels notably. Besides, it was possible to see a higher participation and motivation for classes in which reading, writing and art are involved.

\section{Key words:}

Didactic sequence, reading, writing, literature, art, texts production, texts comprehension.

\section{Resumo}

Este artigo apresenta os resultados de um projeto de pesquisa-ação realizada com crianças do primeiro grau, centro detalhado José María Córdoba, IED, Bogotá, DC O objetivo foi investigar estratégias pedagógicas que facilitem a compreensão de texto e produção. A análise dos dados mostra que os estudantes envolvidos no processo de ter melhorado significativamente os níveis de compreensão de texto e produção. Maior participação e motivação também é conhecida por classes que envolvem a leitura, escrita e arte.

Palavras chave:

Ensino seqüência, leitura, escrita, literatura, arte, produção de texto, compreensão de texto. 
Yo jugué con mi amigo Santiago con las cartas, a que son poderes de dragones y que también nos podíamos convertir en huevos de dragones en las colinas, corriendo de bajada y subida en el parque.

Anécdota de Daniel García, Centro Integral José María Córdoba IED, grado 102 JT, 2014.

\section{Introducción}

$\mathrm{E}$ lenguaje es una herramienta que le ha permitido al ser humano representar la realidad, estructurar su pensamiento y construirse como ciudadano. Por ello, en los últimos tiempos, se han implementado diferentes programas que desde la escuela, la familia y las bibliotecas fortalezcan los procesos del lenguaje a partir de nuevas prácticas de lectura y escritura, concebidas como prácticas sociales y culturales.

Por su parte, el Ministerio de Educación Nacional de Colombia (en adelante, MEN) implementó el Plan Nacional de Lectura y escritura - "Leer es mi cuento", enmarcado en la trasformación de las prácticas de enseñanza de la lectura y la escritura. El plan se constituye en una invitación para que maestros, maestras, bibliotecarios y familias, trabajen con el objeto de transformar y fortalecer los procesos de la lectura y la escritura, a través de la generación de nuevos espacios y situaciones en las que los niños, niñas y jóvenes participen significativamente y reconozcan la función y el uso social de la lectura y escritura para la vida.

$\mathrm{Al}$ respecto, conviene decir que el Instituto Colombiano para la Evaluación de la Educación (en adelante, ICFES), manifestó que los resultados obtenidos por los estudiantes del Centro Integral José María Córdoba IED, en el año 2013, en la prueba Saber $3^{\circ}$ del área de lenguaje, evidencian, por ejemplo, que el $10 \%$ de ellos está en un nivel insuficiente, $26 \%$ en el mínimo, apenas el $38 \%$ en satisfactorio y solo el $26 \%$ está en el avanzado (Junio, 2014). Además, los resultados en la prueba Saber $5^{\circ}$, del mismo año en el área de lenguaje, evidencian que el 11\% de los estudiantes están en un nivel insuficiente, $37 \%$ en el mínimo, el 37\% en satisfactorio y solo el 15\% está en el avanzado (Junio, 2014).

Por lo anterior, se consideró la necesidad de reflexionar sobre las prácticas de enseñanza de la lectura y la escritura que se realizan en el ciclo inicial, para, desde allí, implementar una estrategia pedagógica que facilitara la comprensión y la producción textual en las niñas y niños del grado primero (102 JT), siendo procesos que deben realizarse de forma trasversal y a lo largo de la vida, en tanto, áreas como matemáticas, ciencias sociales y ciencias naturales, requieren de estos procesos para comprender e interpretar también su realidad.

\section{Justificación}

El desarrollo del lenguaje es un proceso cultural y social. Por lo tanto, la familia, la escuela y las entidades gubernamentales y no gubernamentales, deben fomentar y fortalecer espacios reflexivos y pedagógicos en donde la lectura y la escritura sean prácticas que ayuden al sujeto a participar plenamente en la sociedad, así:

La lectura va más allá de la noción de decodificación y desciframiento, implica que la lectura involucra la comprensión de información escrita con distintos propósitos, su uso y la posibilidad de reflexionar sobre su sentido, no por el deber escolar, sino por la necesidad de resolver situaciones vinculadas con la vida cotidiana. De esta forma se tiene en cuenta el papel activo e interactivo del lector al interpretar significados a partir de los textos escritos (Jurado, Fabio, 2014, p. 44).

$\mathrm{Al}$ respecto, conviene decir que el MEN, desde las secretarías de educación, ha fortalecido programas para el fomento de estas prácticas, no solo para estudiantes, sino para maestros; los bajos resultados pueden ser consecuencia de sus prácticas y concepciones sobre la lectura y la escritura, ya que se ha visto que priman ideas en las que la lectura no es más que una decodificación de signos y la escritura meramente transcripción.

Ahora bien, sin mejorar las habilidades y competencias comunicativas no será posible hablar de una educación de calidad en Colombia; ya que si partimos de la concepción del lenguaje como: "[...] la construcción de sentidos y significados a través de los múltiples códigos y formas de simbolizar, las formas como establecemos interacciones con otros humanos y también con procesos a través de los cuales nos vinculamos a la cultura y sus saberes" (MEN, 1998), nos daremos cuenta de que el lenguaje es aquello que nos diferencia de otros seres y nos permite conocer y expresarnos acerca de todo aquello que nos rodea.

Durante varios años Colombia ha participado en diferentes programas y estudios internacionales para evaluar los procesos 
de comprensión de lectura y escritura de niñas, niños y jóvenes de diferentes regiones del país. El Laboratorio Latinoamericano de Evaluación de la Calidad de la Educación (en adelante, LLECE) realizó el segundo estudió regional comparativo y explicativo (en adelante, SERCE) con el fin de revelar los resultados de las pruebas de Lectura y Escritura, SERCE, aplicadas a estudiantes de tercero y sexto de América Latina y el Caribe (diecisiete países), entre los años 2002 y 2008, y proporcionar ideas para elevar la calidad de la enseñanza de estas prácticas.

Por un lado, SERCE (2012) afirmó que: "el aprendizaje de la lectura se realiza a través de la interacción con una variedad de textos", a través de: "La macro-habilidad, entendida como el conjunto de destrezas específicas implicadas en el acto de leer y comprender lo leído" (p. 24). Por lo anterior, la prueba de lectura: "se fundó en una macro-habilidad para la vida: interpretar y resolver de manera acertada problemas comunicativos a partir de información escrita situada en diversos textos auténticos" (p. 23).

El resultado de la prueba evidenció que los estudiantes colombianos de tercer grado se encuentran en un nivel medio en el desempeño para identificar textos narrativos como el cuento, mientras que están en un nivel alto en la identificación de una historieta. La prueba arrojó resultados que ubican a los estudiantes en un nivel alto en cuanto a la identificación de textos argumentativos, como el afiche.

Por otro lado, en 2009 el país participó en la prueba PISA (Programa Internacional para la Evaluación de Estudiantes), que, para este año, tuvo énfasis en lectura. El resultado reveló que un $47 \%$ de los estudiantes de quince años, que presentaron la prueba que en Colombia, se encuentra por debajo del nivel mínimo aceptable según los estándares de PISA. El MEN (2010) afirma:

Un buen nivel de lectura es la base no solo para que los estudiantes logren mejores aprendizajes en áreas como matemáticas y ciencias, sino también para que desarrollen un pensamiento crítico y autónomo para participar activa y constructivamente en la sociedad. No alcanzarlo pone en riesgo sus posibilidades de culminar sus estudios e insertarse exitosamente en la vida social, cultural y productiva (s. p).

Por consiguiente, es necesario que la comunidad educativa diseñe propuestas pedagógicas que transformen las prácticas de enseñanza y aprendizaje, y que propicien la formación de lectores y escritores a partir las prácticas sociales del lenguaje, en beneficio de las niñas y niños de los colegios oficiales de la Capital.

En este sentido, la implementación de la secuencia didáctica "Si mi entorno quiero conocer, leyendo y escribiendo más fácil es", fue una oportunidad, en ciclo inicial, que precisamente contribuyó a transformar las prácticas de enseñanza de lectura y escritura, con niños y niñas de grado primero (102 JT), en el Centro Integral José María Córdoba IED; además facilitó la comprensión y producción textual, a través de la literatura y de otros lenguajes artísticos, que fueron utilizados como herramientas que permiten conocer el mundo, crearlo y recrearlo; viéndolos como instrumentos que permiten generar preguntas, establecer relaciones y construir el pensamiento a través de las historias de vida que rodean a las niñas y niños.

\section{Contexto donde se desarrolló la investigación}

La institución educativa en la que se realizó la investigación está ubicada la localidad seis de Bogotá, D.C. Su horizonte se define a partir del Proyecto Educativo Institucional: "Formación humanista para una vida trascendente y productiva", el cual busca fortalecer y enriquecer el conocimiento científico, técnico y humanístico, desarrollando en los estudiantes sus dimensiones socio-afectivas, psicomotores e intelectuales, con el fin de lograr una persona autónoma para guiar su propio destino, consciente de sus responsabilidades sociales y con elementos básicos para una futura formación (Manual de convivencia, 2014).

En relación con la investigación, es fundamental señalar que ésta se realizó con los estudiantes del grado 102 JT (33 estudiantes), que oscilan entre los seis (6) y ocho (8) años de edad. La mayoría de ellos realizaron sus estudios de preescolar (únicamente transición) en la institución; otros, son repitentes o vienen de preescolar de otros colegios públicos y privados de los alrededores de la institución. El grupo se conforma de 13 niñas y 20 niños, población que presenta, entre otras características: diversos ritmos de aprendizaje, necesidades educativas especiales y transitorias y un gran porcentaje de alumnos repitentes. 


\section{Referentes teóricos}

\section{Pedagogía}

En primer lugar, la investigación tuvo una estrecha relación con las prácticas de enseñanza del maestro, las cuales hacen parte de la esencia de la pedagogía. En este sentido, la Escuela Normal Superior Distrital María Montessori (2014), afirma que la pedagogía: "Se constituye en el saber fundante de la profesión docente, es el saber que identifica al maestro y que le permite al profesional de la educación desarrollar una conciencia y una apropiación social de su función y de la praxis educativa” (s. p.). Al respecto, el profesor Gustavo Arias Arteaga (2002) considera que:

La educabilidad, como atributo de la Pedagogía, sí es referente obligado para considerar desde la enseñabilidad las decisiones que favorecen que una ciencia sea enseñada por un maestro y su aprendizaje suscite transformaciones en los aprendices, evidenciando que desde la estructura misma de las disciplinas, éstas se hacen comunicables, misión que el pedagogo estructura a través de una didáctica ya considerada como una "práctica reconstructiva" o considerada como cuerpo teórico que reflexiona sobre el saber que se enseña y su influjo en los seres humanos (p. 7).

\section{Lenguaje}

El lenguaje es entendido como la construcción de sentidos a través de los múltiples códigos y formas de simbolizar; un proceso complejo que se da en el ámbito histórico, social y cultural. El lenguaje y sus procesos no solo se concentran en la construcción de la comunicación, sino en la del significado, entendido como los diferentes caminos en los cuales los sujetos llenan de valor los signos. $\mathrm{Al}$ respecto, el MEN afirma:

Es a través del lenguaje que se configura el universo simbólico y cultural de cada sujeto -claro está que en relación e interacción con otros sujetos culturales; pero esa característica de reconocimiento del proceso a través del cual el sujeto llena el mundo de significados y a la vez configura su lugar en el mundo (1998, p. 25).
Del mismo modo, una de las primeras funciones del lenguaje es la comunicación y el intercambio social, con los cuales es posible interactuar con la cultura y la sociedad; Vygotsky (1995) afirma que: "[...] la transmisión racional, intencional, de la experiencia y el pensamiento a los demás, requiere un sistema mediatizador, y el prototipo de éste es el lenguaje humano nacido de la necesidad de intercomunicación durante el trabajo" (p. 18).

Desde aquí, surge la importancia del lenguaje en los actos de comunicación y en la función social que le subyace; así, la lengua desempeña una función comunicativa significativa en el lenguaje, es en este sentido que Halliday considera que la lengua es: "[...] el canal principal, por lo que se le transmite a los sujetos modelos de vida, por el que aprenden a actuar como miembros de una sociedad [...] y adoptar su cultura, sus modos de pensar y de actuar, sus creencias y valores (citado en SED, 2010).

Es a través de la comunicación, entendida como un proceso de intercambio y construcción de significados, que desde los primeros años de vida el sujeto establece ciertas relaciones importantes en su vida social y cultural, las cuales hacen posible la convivencia y la confianza en los demás para interactuar con ellos. Por ello Frabboni y Bertolini piensan que la comunicación es un: "proceso que posibilita el tejido social, cultural y político, que permite al individuo acceder al mayor número de experiencias y conocimientos" (citado en SED, 2010).

Del mismo modo, el lenguaje en la educación inicial no depende únicamente del desarrollo de los niños, sino también de las experiencias significativas que tengan en su entorno sociocultural. Pensando de la misma forma, Reyes establece que el desarrollo del lenguaje no depende de los esfuerzos individuales de los niños, sino de lo que su ambiente social y cultural les ha brindado o negado durante los primeros años de vida (citado en SED, 2010).

\section{Lectura}

La lectura es un proceso de construcción de significados a partir de la interacción entre el texto, el contexto y el lector. El significado, a diferencia de lo que sostenía el modelo perceptivo en la matriz de la lectura, no está solo en el texto, tampoco en el contexto, ni en el lector, sino en la interacción de los tres factores, los cuales determinan la comprensión (MEN, 1998). Así, Jolibert (2002) considera que saber leer es una necesidad indispensable y que no solo se lee el código alfabético, sino el sonido y las ilustraciones: La lectura placentera en el lector lo 
hace descubrir mundos diferentes, por tanto, la escuela, como espacio de posibilidad cultural y social, debe fomentar espacios donde la lectura sea significativa y placentera para los sujetos.

En el mismo sentido, Yolanda Reyes (citada en SED, 2010) considera que la promoción de la lectura desde la escuela debe hacerse a partir de una experiencia personal, es decir, quien promocione en estos espacios la lectura y sea mediador entre el texto y el lector, debe tener una experiencia de lectura enriquecedora con la que pueda contagiar a sus estudiantes, entender que los niños llegan a la escuela con un cierto patrimonio literario transmitido de manera oral por familiares, con su soporte en el ritmo, en las formas, en la música, en el juego.

Del mismo modo, el MEN (1998) afirma que se deben facilitar algunas estrategias, incluidas en el mismo proceso de la lectura, para la comprensión lectora en el contexto educativo del sujeto, así como estrategias pedagógicas que abarquen el antes, durante y después de la lectura: "Las actividades antes y durante pretenden focalizar en los niños la atención, despertar su interés, activar el conocimiento previo, movilizar los procesos imaginativos y creativos, y promover la predicción" (p. 97). En este contexto cobran sentido las afirmaciones de Josette Jolibert (citada por Peña, 2012) cuando considera que: "Leer es leer escritos verdaderos, que van desde un nombre en un letrero, a un libro, pasando por un afiche, un embalaje, un diario, un panfleto, etc., en el momento en que tenemos verdadera necesidad, en una situación de vida precisa". Por ello Isabel Solé (citada en SED, 2010) propone unas estrategias para la enseñanza de la lectu$\mathrm{ra}$, teniendo en cuenta las operaciones cognitivas que se activan antes, durante y después de la misma. Así, antes de la lectura es necesario, desde el título y las imágenes, invitar al niño a hablar sobre el contenido del texto, indagando sus conocimientos previos; durante la lectura resulta apropiado suspenderla para escuchar comentarios e invitar al niño a predecir, en forma verbal o escrita, el final del texto; para después de la lectura es importante invitar a los niños a que den cuenta de lo que dice el texto y a que reconstruyan las redes conceptuales que habitan en él.

\section{Escritura}

La escritura es parte fundamental en el desarrollo del lenguaje; otra de las formas en que el sujeto manifiesta realidades, deseos o posturas. El lenguaje escrito, desde su estructura y forma de funcionamiento, es una función lingüística separada del lenguaje oral. En la escritura se manifiestan intenciones comunicativas con un alto nivel de complejidad pero con una misma intención comunicativa. Así, Vygotsky (1995), afirma:

\begin{abstract}
El niño tiene muy poca motivación para aprender a escribir cuando se le empieza a enseñar. No siente la necesidad de hacerlo y tiene solo una vaga idea de su utilidad. En la conversación cada frase está impulsada por un motivo; el deseo o la necesidad conducen a efectuar pedidos, las preguntas a solicitar respuestas, y la perplejidad a pedir una explicación. Las motivaciones cambiantes de los interlocutores determinan en cada momento el rumbo que tomará el lenguaje oral, que no tiene la necesidad de ser conscientemente dirigido, la situación dinámica se hace cargo de ello. Las motivaciones para la escritura son más abstractas, más intelectualizadas y están más distantes de las necesidades inmediatas. En el lenguaje escrito estamos obligados a crear la situación, a representárnosla. Esto requiere una separación de la situación real (p. 75).
\end{abstract}

La escritura, desde la perspectiva de Vygotsky, debe ser algo natural para el niño, no algo impuesto. Al momento de escribir, debe comprender los sonidos (fonemas) de cada palabra, examinarlos y representarlos en símbolos alfabéticos, los cuales tuvo que haber memorizado y estudiado para finalmente colocar las palabras en secuencia y formar una oración. Lo anterior implica el acompañamiento constante del adulto o el maestro, y la escuela debe privilegiar espacios y tiempos significativos donde se desarrollen los procesos de lenguaje. La experiencia ha demostrado que el niño con una zona más amplia que la de su desarrollo próximo tendrá un mejor rendimiento escolar, y lo que el niño puede hacer hoy en cooperación, mañana podrá hacerlo solo.

El lenguaje escrito es la forma más elaborada del lenguaje y, por consiguiente, requiere de bastante esfuerzo por parte de quien escribe; también debe ser riguroso y, por tanto, debe llegar a elaborar el texto a partir de unas fases en la escritura, como el escrito en borrador y en limpio, para que ésta sea significativa.

En el lenguaje escrito, donde falta una base situacional y expresiva, la comunicación solo puede ser lograda a través de las palabras complicadas, de ahí el uso de los borradores. La diferencia entre el borrador y la copia final refleja nuestro proceso mental. La planificación es importante en el lenguaje 
escrito, aún cuando no confeccionemos un borrador. Generalmente nos decimos a nosotros mismos lo que vamos a escribir; esto también es un borrador, aunque solo mental (Vygotsky, 1995, p.106).

Vygotsky también considera que la escritura es un proceso social e individual en el que se configura un mundo y se ponen en juego saberes, competencias e intereses que a la vez están determinados por un contexto social y pragmático. Así, siendo la escritura un mundo de tejidos de significados con una intención comunicativa, Emilia Ferreiro y Ana Teberosky (citadas en Negret, 2008) descubrieron que los niños pasan por muchas y originales formas de construcción de la escritura alfabética, que implican cuatro etapas: Una previa a la escritura silábica, en la que los niños y niñas usan garabatos, pseudoletras y letras dispuestas al azar; una "hipótesis alfabética", en la que los niños escriben usando una letra por sílaba -que puede ser una consonante o una vocal-; una "silábico-alfabética" de transición hacia la última: la "alfabética", en la que los niños ya escriben con vocales y consonantes.

En este contexto, vale la pena resaltar los diferentes tipos de textos con los que el niño y el maestro de educación inicial se pueden encontrar, para, desde allí realizar talleres significativos de producción textual: los textos informativos como el afiche, la carta y la circular: los textos narrativos, como el cuento, la obra de teatro, la historieta y el relato cotidiano; y los textos explicativos, como la receta, las reglas de juego y las instrucciones para armar un juguete.

Construir textos no solo requiere de competencias lingüísticas sino que, como lo señala Josette Jolibert (citada en Peña, 2012):

[...] se debe construir respecto a las competencias (saber hacer), conductas (saber ser), en conocimientos (saberes en general) indispensables para la construcción de textos [en la] [...] utilidad y las diferentes funciones de la escritura [del] poder que otorga el dominio adecuado de la escritura [y] el placer que puede producir la producción de un escrito: placer de inventar, de construir un texto, de comprender cómo funciona (p. 44).

Por su parte, Fabio Jurado (2014), considera que:

Todo texto responde a un propósito comunicativo, está dirigido a alguien y presenta un contenido organizado de acuerdo con formas convencionales -los géneros de textos-, que a su vez presentan secuencias predominantes, como narrativa, explicativa, descriptiva argumentativa e instruccional (p.44).

Por otro lado, Rita Flórez y Clemencia Cuervo (1992) afirman que no es posible concebir la escritura como un producto terminado, que aparece mágicamente en un único y rápido acto. Por el contrario, es necesario interpretarla como la composición de una obra de arte que, por humilde que sea, requiere de un trabajo artesanal.

Escribir es un acto complejo porque impone demandas simultáneas sobre el escritor. Cuando una persona escribe tiene que ocuparse de buscar contenidos y generar nuevas ideas, decidir cómo organizar el texto, pensar a qué audiencia va dirigido, tener muy claro qué efecto quiere lograr, manejar el lenguaje para conseguir ese efecto, utilizar la sintaxis correctamente, seleccionar vocabulario, tomar decisiones sobre mecanismos de estilo, asegurar la coherencia y la lógica del texto, no cometer errores de ortografía, producir un texto claro y transparente, lograr un texto que tenga energía, utilizar adecuadamente la puntuación para comunicar los significados deseados y controlar la longitud del texto (p. 1).

Por lo anterior, las autoras sugieren tres subprocesos en el acto de escribir: planificar el texto; revisarlo o corregirlo y, finalmente, editarlo, lo cual que refleja la versión final del texto.

\section{Literatura}

La literatura, como lenguaje artístico, lleva al sujeto a mundos posibles a través de la imaginación. En este sentido, la SED (2010), afirma:

Es el arte de jugar con el lenguaje -no solo con el lenguaje verbal, ni exclusivamente con el lenguaje escrito, sino con múltiples lenguajes- para imprimir las huellas de la experiencia humana, elaborarla y hacerla comprensible a otras personas. Esa voluntad estética que nos impulsa a crear, recrear y expresar nuestras emociones, nuestros sueños y nuestras preguntas, para contarnos: "noticias secretas del fondo de nosotros mismos", es un lenguaje simbólico, es fundamental en el desarrollo infantil (p. 56). 
Leer de viva voz permite al niños explorar sus emociones, compartir y expresar sus temores y sus sueños, identificarse con los personajes, adquirir nuevo vocabulario y familiarizarse con el funcionamiento de la lengua escrita, mediante operaciones como anticiparse, interpretar, hacer inferencias y comentar las historias, sin que ello implique obligarles a contestar preguntas sobre lo leído, sino más bien, motivarles a conversar, en un ambiente espontáneo, sobre los libros y sus vidas (p.62).

Yolanda Reyes (citada en MEN, 2013) considera que la literatura debe ser leída y sentida desde la propia vida. El que escribe estrena las palabras y las reinventa cada vez para imprimirles su huella personal. El que lee literatura recrea ese proceso de invención para descifrar y descifrar-se en el lenguaje secreto de otro.

\section{Arte en educación inicial}

Los diferentes lenguajes artísticos (pintura, música, danza, escultura y plástica) generan experiencias significativas en los sujetos, que aportan a su desarrollo integral; por ello, la SED (2010), afirma:

El arte involucra al descubrimiento y el disfrute de diversas sensaciones; invita a los niños y las niñas, con la orientación de maestros y maestras, a experimentar a partir de las diferentes posibilidades que les ofrece su cuerpo y el manejo de distintos materiales. Las experiencias artísticas son en sí mismas una excelente oportunidad para expresar, comunicar, representar, apreciar, descubrir y crear desde la vivencia con otros y con el entorno (p.63).

\section{Estrategia metodológica}

El enfoque metodológico que se utilizó para este proyecto fue la investigación cualitativa. El diseño a seguir es la investigación acción participativa, en tanto se centró en detectar el problema, formular una propuesta didáctica, implementarla y finalmente retroalimentar los resultados.

\section{El método}

En principio se empleó una recolección de datos; proceso que implicó el uso de varias técnicas:

- Instrumentos de caracterización inicial de comprensión y producción textual. Para recoger la información sobre la comprensión y producción de textos antes de la implementación de la secuencia didáctica, se utilizaron instrumentos que evidenciaron el nivel de comprensión de lectura y la producción de textos. Además, antes de implementar la secuencia, se recogió información a partir de algunos cuadernos de los estudiantes.

- Creación y diseño de la secuencia didáctica "Si mi entorno quiero conocer, leyendo y escribiendo más fácil es”. Esta técnica fue guiada por los planteamientos de Camps (2003), quien afirma que:

La secuencia está constituida por un conjunto de tareas diversas, pero todas ellas relacionadas con un objetivo global que les dará sentido. Lo que le otorga unidad al conjunto no es solo el tema, sino la actividad global implicada, la finalidad con que se llevan a cabo [...] La secuencia está constituida por un conjunto de tareas diversas, pero todas ellas relacionadas con un objetivo global que les dará sentido. Lo que le otorga unidad al conjunto no es solo el tema, sino la actividad global implicada, la finalidad con que se lleva a cabo (p. 3).

Durante los meses de Agosto, Septiembre, Octubre y Noviembre de 2014, se implementó la estrategia a partir de los resultados de las pruebas iniciales, intereses y necesidades de los estudiantes.

Rejillas de análisis

- Se valoró la producción de texto (Cohesión, coherencia, ortografía, entre otros) a través de una rejilla de análisis para observar el proceso que tuvieron los estudiantes en la elaboración del primer y segundo borrador. 
- Se valoró la comprensión de lectura (literal, inferencial e intertextual) a través de una rejilla de análisis que consideró las actividades realizadas por los estudiantes antes, durante y después de la lectura.

- Diario de campo, videos y fotografías.

\section{Resultados}

\section{Fases de la secuencia}

\section{Preparación}

En esta fase se diseñaron los propósitos de la secuencia didáctica, a partir de intereses y necesidades de los estudiantes, los aprendizajes esperados (saber cognitivo procedimental - actitudinal) y los recursos humanos y físicos que se utilizarían.

\section{Produción}

A partir del propósito y los aprendizajes esperados, cada actividad de la secuencia didáctica empezó con motivar a los estudiantes a realizar las actividades desde sus conocimientos previos y mediante preguntas orientadoras que guiaran el proceso de comprensión y producción de textos.

\section{Evaluación}

Construcción de rejillas de análisis que valoraron el proceso de comprensión y producción de textos de los estudiantes.

\section{Momentos de la secuencia}

- $\quad$ Actividad 1: Festival de cometas.

- $\quad$ Actividad 2: La caída de mis dientes.

- Actividad 3: Los esqueletos y yo podemos bailar.

- Actividad 4: La magia de la navidad.

\section{Definición de categorías y subcategorías de análisis}

Las categorías que se presentan a continuación fueron utilizadas para analizar los resultados alcanzados, en relación con la comprensión y producción de textos, por los niños y niñas del grado primero. Surgieron de los datos obtenidos en el proceso de investigación (marco teórico, diario de campo, entrevistas orales, fotografías, videos, actividades realizadas y creaciones artísticas).

\begin{tabular}{c|c} 
Categorías & \multicolumn{1}{|c}{$\begin{array}{c}\text { Subcategorías } \\
\text { Competencia semántica; } \\
\text { Competencia pragmática o } \\
\text { socio-cultural; Competen- } \\
\text { cia enciclopédica; } \\
\text { Competencia literaria }\end{array}$} \\
Producción textual & $\begin{array}{l}\text { Competencia semántica; } \\
\text { Competencia pragmática o } \\
\text { socio-cultural; Competen- } \\
\text { cia enciclopédica; } \\
\text { Competencia literaria }\end{array}$ \\
Leguajes artísticos & $\begin{array}{l}\text { Literatura, artes plásticas, } \\
\text { música, danza }\end{array}$
\end{tabular}

Tabla 1. Categorías

A partir del análisis del primer instrumento, que buscó caracterizar la comprensión y producción textual de los estudiantes del grado 102 JT; se pudo ver que:

\section{Comprensión textual-Instrumento}

En el mes de Abril de 2014, se realizó un taller para la comprensión de lectura a partir del cuento de Ellen Stoll Walsh: "Cuenta ratones". Para hacerlo, se llevó a cabo una lectura en voz alta que utilizó las estrategias que comprenden el proceso antes, durante y después de la lectura, también se empleó la técnica de uso de plastilina para reconstruir la historia a través de una obra artística, y se desarrollaron procesos que implicaban la oralidad. 


\section{Antes de la lectura}

Los estudiantes utilizan sus conocimientos previos para compartir experiencias sobre sus historias de vida. Si bien todos quisieron participar en el conversatorio, aún se les dificulta el respeto por la palabra y la capacidad de escucha.

Aunque no todos participaron, escucharon la historia atentamente. Todos quisieron tomar en sus manos el libro, por lo que se requiere de otra estrategia para que puedan observar las imágenes más de cerca.

\section{Durante la lectura}

Durante la segunda lectura del cuento los estudiantes participaron de un taller que representaba una imagen de los personajes de la historia, la cual tuvieron que interpretar $y$, desde allí, predecir un posible final para la historia. Este momento ayudó a que los estudiantes conversaran y compartieran sus predicciones sobre el final de la historia. Además, facilitó el uso de la representación pictórica para representar un posible final para la historia.

\section{Después de la lectura}

Se dieron dos momentos: En la sala de informática los estudiantes tuvieron la oportunidad de acercarse a la historia desde un formato digital; por medio de los computadores observaron el libro digital, mientras atendían a la lectura en voz alta y mental (algunos leen las palabras, otros, las imágenes).

Finalmente, los estudiantes representaron la historia por medio de una obra artística (técnica de la plastilina).
Tabla 2. Resultados recogidos a través del diario de campo y del análisis del trabajo según los momentos de la lectura.

\section{Producción textual-instrumento}

Durante el primer período académico del año 2014, se pudo observar que apenas el 30\% de los 33 estudiantes, que entraron en el mes de Enero al grado primero, era capaz de escribir palabras utilizando el código alfabético; mientras que el $70 \%$ restante escribía a través de imágenes, vocales, sílabas y algunas palabras. Durante el primer semestre de este año se realizaron talleres que facilitaran la escritura alfabética de los estudiantes. Esta información se recogió a través de los cuadernos de escritura de los estudiantes y de un instrumento para valorar su producción escrita.

\section{Análisis de la información recogida}

Las actividades realizadas en cada momento de la secuencia didáctica fueron recogidas a través de una carpeta que evidenciaba el proceso del estudiante. A partir de esta información, se diseñaron unas rejillas para analizar la comprensión y producción textual de cada estudiante, con el objetivo de valorar el impacto de la implementación de la secuencia.

\section{Hallazgos preliminares}

- A través de las actividades frente a la producción escrita (escritura de anécdota, carta, receta, canciones y cuentos), fue posible observar que el $70 \%$ de los estudiantes del grado 102 JT alcanzó la producción de textos auténticos, con sentido e intención comunicativa.

- Los conocimientos previos de los estudiantes y sus historias de vida permitieron formar una micro-comunidad de escritores dentro del aula; también incentivó a otros compañeros del mismo colegio a escribir con sentido.

- La literatura infantil y otros lenguajes artísticos lograron facilitar y motivar a los estudiantes a escribir con gusto y placer y a comprender diferentes tipos de texto.

- La rescritura de los textos fue un recurso que invitó constantemente a los estudiantes a mejorar sus escritos (aspectos gramaticales y de sentido). 


\section{Conclusiones}

Con respecto a las prácticas de enseñanza, se puede concluir que fue posible:

- Utilizar la lectura en voz alta dentro del aula. Es un instrumento que permite desarrollar habilidades comunicativas como la oralidad y la escucha en los estudiantes; además son prácticas que facilitan el acercamiento a la literatura infantil.

- La reflexión constante en la utilización de recursos didácticos en el aula, relacionada a los procesos de lenguaje; este proceso permite identificar y actuar frente a las necesidades y los intereses de los estudiantes.

- Utilizar diferentes lenguajes artísticos (danza, cine, plástica, música y literatura), pues plantean caminos para que estudiantes le den sentido a la lectura y la escritura.

- La posición crítica frente al quehacer pedagógico; esto permitió la producción de textos auténticos dentro del aula.

- El diseño de las rejillas de análisis para la valoración de la comprensión y producción de textos; este ejercicio facilitó la realización de una valoración continua y permanente de los procesos individuales y colectivos de los estudiantes.

Con respecto a los procesos de lectura y escritura de los estudiantes, se puede concluir que:

- La secuencia didáctica facilitó procesos de comprensión y producción de textos a través de actividades intencionalmente diseñadas.

- Los estudiantes iniciaron un proceso significativo de revisión de textos y comprensión de lectura a través del recurso de la lectura en voz alta.

- El acercamiento a diferentes tipos de texto fue una herramienta que permitió visibilizar el pensamiento de los estudiantes a través de la escritura, la lectura y la oralidad.

- El proyecto tenía como objetivo facilitar la comprensión y producción textual, pero también con- tribuyó al desarrollo de la oralidad por medio de la lectura en voz alta y las estrategias de antes, durante y después de la lectura.

- Los resultados evidencian que es necesario seguir fortaleciendo las habilidades comunicativas, en tanto son procesos que se desarrollan a lo largo de la vida, y es la escuela la que debe crear micro-comunidades de lectura y escritura para, así, formar lectores y escritores competentes.

- La lectura y escritura aportan significativamente al desarrollo del pensamiento y, sin duda, a mejorar la calidad de la educación en Colombia; es en el ciclo inicial donde se puede realizar un aporte significativo. 


\section{Referencias}

Atorresi, A. (2012). Aportes para la enseñanza de la lectura. Santiago de Chile: SERCE- UNESCO.

Camps, A. (2003). Secuencias didácticas para aprender a escribir. Barcelona: Graó.

Centro Integral José María Córdoba IED. (2014). Manual de Convivencia. Bogotá: Centro Integral José María Córdoba IED.

Escuela Normal Superior Distrital María Montessori. (2014). Agenda estudiantil. Bogotá: María Montessori.

Florez, R., y Cuervo, C. (1992). La escritura como proceso. Bogotá: Universidad Nacional de Colombia.

Jolibert, J. (2002). Formar niños productores de textos. Santiago de Chile: Dolmen.

Jurado, F. (2014). La lectura en las escuelas de la periferia. Bogotá: Universidad Nacional de Colombia.

Instituto Colombiano para la Evaluación de la Educación. (2014). Resultados en tercer grado en el área del lenguaje. Obtenido el 13 de Octubre de 2014, desde http://www2.icfesinteractivo.gov. co/ ReportesSaber359/consultaReporteEntidadTerritorial.jspx

MEN. (1998). Lineamientos de Lengua Castellana. Bogotá: Cooperativa Magisterio.

MEN y Colombia Aprende. (2014). Plan Nacional de Lectura y Escritura "Leer es mi cuento". Obtenido el 13 de Octubre de 2014, desde http://www.colombiaaprende.edu.co/html/microsi tios/1752/w3-propertyname-3032.html

MEN. (2006). Estándares básicos de competencias en lenguaje, matemáticas, ciencias y cuidadanía. Bogotá: Imprenta Nacional de Colombia.

MEN. (2010). Colombia en PISA 2009. Obtenido el 13 de Octubre de 2014, desde http://www. mineducacion.gov.co/cvn/1665/w3-article-257876.html
MEN. (2013). Ministerio de Educación nacional. Obtenido el 3 de Mayo de 2014, desde http://www.mineducacion.gov.co/1621/ w3-propertyvalue-49672.html

MEN. (2013). LEER para comprender; ESCRIBIR para transformar. Palabras que abren nuevos caminos en la escuela. Bogotá: Plan Nacional de Lectura y Escritura.

Negret, J. C. (2008). Portafolio del educador. Bogotá: Herramientas y Gestión.

Peña, L. A. (2012). Didáctica del lenguaje en una perspectiva ética, epistémica y estética de la comunicación y el discurso. Revista Internacional Magisterio, pp. 42-48.

Restrepo, B. (2002). Investigación en educación. Instituto Colombiano para el Fomento de la Educación Superior, ICFES. Bogotá: ARFO.

SED. (2007). Orientaciones curriculares para el campo de comunicación, arte y expresión. Bogotá: SED.

SED. (2010). Referentes para la Didactica del Lenguaje en primer ciclo. Bogotá: SED.

SED. (2010). Referentes para la Didáctica del Lenguaje en el segundo ciclo. Bogotá: SED.

Secretaría de Educación de Bogotá y Secretaría de Integración social. (2010). Lineamiento pedagógico y curricular para la Educación Inicial en el Distrito. Bogotá: Imprenta Nacional de Colombia.

Vygotsky, L. S. (1995). Pensamiento y Lenguaje. Obtenido el 5 de Diciembre de 2013, desde Psikolibro: http://psikolibro.blogspot. com 